workers. Indeed, institutions and governments should consider preventing free marketing of FFR with valves, given that their indiscriminate use in the community setting can determine an additional and under tracked risk for the population.

Acknowledgments. None.

Financial support. No financial support was provided relevant to this article.

Conflicts of interest. All authors report no conflicts of interest relevant to this article.

\section{References}

1. Anfinrud P, Stadnytskyi V, Bax CE, Bax A. Visualizing speech-generated oral fluid droplets with laser light scattering. $N$ Engl J Med 2020 Apr 15 [Epub ahead of print]. doi: 10.1056/nejmc2007800.

2. Using face masks in the community reducing COVID-19 transmission from potentially asymptomatic or pre-symptomatic people through the use of face masks. Technical report. European Centers for Disease Control and Prevention website. https:/www.ecdc.europa.eu/sites/default/files/documents/COVID19-use-face-masks-community.pdf. Accessed May 5, 2020.

3. New York Gov. Andrew Cuomo orders all people to wear face coverings in public. CNBC website. https:/www.cnbc.com/2020/04/15/new-york-govcuomo-to-order-all-people-to-wear-masks-or-face-coverings-in-public. html. Accessed May 5, 2020.
4. Ippolito M, Vitale F, Accurso G, et al. Medical masks and respirators for the protection of healthcare workers from SARS-CoV-2 and other viruses. Pulmonology 2020 Apr 27 [Epub ahead of print]. doi: 10.1016/j.pulmoe. 2020.04.009.

5. Ippolito M, Iozzo P, Gregoretti C, Cortegiani A. Counterfeit filtering facepiece respirators are posing an additional risk to healthcare workers during the COVID-19 pandemic. Am J Infect Control 2020 Apr 29 [Epub ahead of print]. doi: 10.1016/j.ajic.2020.04.020

6. Kuo YM, Lai CY, Chen CC, Lu BH, Huang SH, Chen CW. Evaluation of exhalation valves. Ann Occup Hyg 2005;49:563-568.

7. Infographic: using face masks in the community. European Centers for Disease Control and Prevention website. https://www.ecdc.europa.eu/en/ publications-data/infographic-using-face-masks-community Accessed May 5, 2020.

8. Community use of face masks. Africa Centers for Disease Control and Prevention website. https://africacdc.org/download/community-use-of-facemasks/. Accessed May 5, 2020.

9. Personal protective equipment: questions and answers. US Centers for Disease Control and Prevention website. https:/www.cdc.gov/coronavirus/ 2019-ncov/hcp/respirator-use-faq.html. Accessed May 5, 2020.

10. Masks and face coverings for the coronavirus outbreak. City and County of San Franciso government website. https://sf.gov/information/masks-andface-coverings-coronavirus-outbreak. Accessed May 5, 2020.

\title{
Aerosol distribution in the cabin and cockpit of an ambulance helicopter
}

\author{
Sebastian Schulz-Stübner Privatdozent Dr. med. ${ }^{1}$, Jürgen Henker Koordinator Hygienemanagement Medizin ${ }^{2}$, \\ Jörg Braun Dr. med. ${ }^{2}$ and Raimund Kosa Stv. Koordinator Hygienemanagement Medizin ${ }^{2}$ \\ ${ }^{1}$ German Consulting Center for Infection Prevention and Control [Deutsches Beratungszentrum für Hygiene (BZH GmbH)], Freiburg, Germany and ${ }^{2}$ DRF Stiftung \\ Luftrettung gemeinnützige AG, Filderstadt, Germany
}

To the Editor-Even before the COVID-19 pandemic, when our study was planned, the question of potential spread of droplets or airborne particles from the patient in the cabin of an air ambulance helicopter into the cockpit was eminent. Transportation of patients with aerogenously transmitted diseases in helicopters is increasingly required, and personal protective equipment cannot be worn by the pilot to the same degree as the medical crew. Also, disinfection of aeronautic equipment in the cockpit is cumbersome. ${ }^{1}$ Therefore, we developed an experimental model to simulate aerosol distribution within the helicopter on the ground and in flight with a worst-case "airborne spread" scenario and a clinically relevant "short, intermittent droplet spread" scenario.

\section{Material and Methods}

The project was approved by the Wissenschaftlicher Arbeitskreis der DRF Stiftung Luftrettung gemeinnützige AG, WAK-ID 24 (Scientific Review Committee). A Cirrus 2 nebulizer

Author for correspondence: Sebastian Schulz-Stübner, E-mail: Schulz-stuebner@bzhfreiburg.de

Cite this article: Schulz-Stübner S, et al. (2021). Aerosol distribution in the cabin and cockpit of an ambulance helicopter. Infection Control \& Hospital Epidemiology, 42: 370-371, https://doi.org/10.1017/ice.2020.259
(Intersurgical GmbH, Siegburger Str. 39, 53757 Sankt Augustin, Germany) was filled with a fluorescent marker fluid (UV-Tinte 4887, Flockenhaus GmbH KG, Frankfurter Str 536124 EichenzellFulda, Germany) and positioned at the head of the patient stretcher, which was positioned at a $30^{\circ}$ angle. For the worst-case scenario, aerosol was produced for 60 seconds with a flow of $8 \mathrm{~L}$ per minute every 5 minutes during flight or on the ground for 30 minutes and for 10 seconds in the short, intermittent scenario on 5 occasions with EC 135 and $\mathrm{H} 145$ Airbus helicopters (Industriestrasse 4, 86609 Donauwörth, Germany) with and without a curtain separating the cockpit from the cabin. In the ground simulation, a test scenario with open aft doors and wind (simulated by a fan) directed into the cabin was added. Aerosol distribution was visualized with ultraviolet light, and the experiment was videotaped. The surface sedimentation was documented using serial photographs.

\section{Results}

Figure 1 gives an impression of the turbulent, undirected distribution of the aerosol. The aerosol filled the cabin on the ground and in flight, independent of helicopter type, ventilation settings, and flight maneuvers, resulting in sedimentation on all surfaces around the patient in the worst-case scenario. Without a curtain, 
(a)

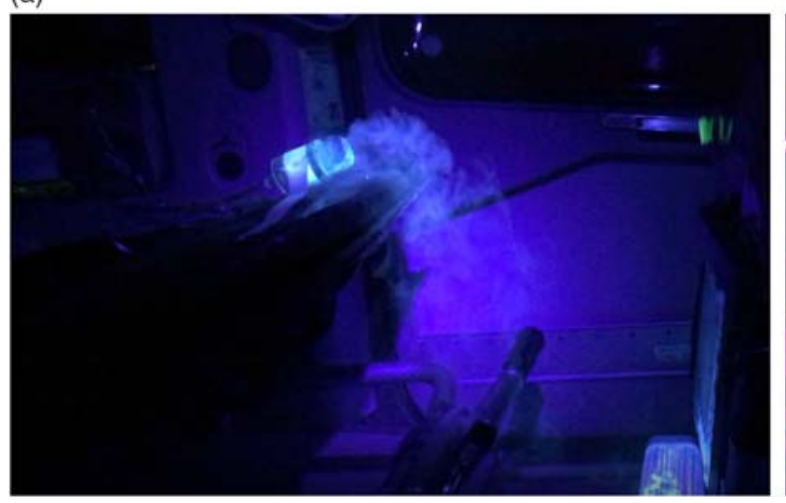

(b)

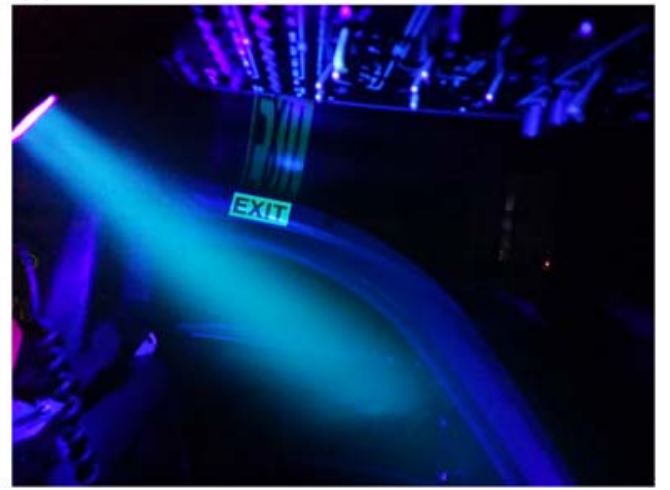

Fig. 1. (a) The setup to visualize the stream of marked aerosol in the cabin. (b) The sedimentation on aeronautic equipment in the cockpit under worst-case conditions.

sedimentation on aeronautic equipment in the cockpit occurred (Fig. 1b); with a curtain, sedimentation was found on the curtain but not in the cockpit.

In the short, intermittent scenario, sedimentation was seen in the cabin and in 1 flight on the curtain but not in the cockpit. Even with doors open and wind from aft in the ground simulation, no sedimentation was observed in the cockpit.

\section{Discussion}

In the confined space of an air ambulance helicopter, massive aerosol production, simulating the conditions of a patient with an airborne transmitted disease, led to direct exposure of the medical crew and sedimentation of particles on all surfaces in the cabin and, without a barrier, on aeronautic equipment in the cockpit, too. However, a simple curtain was sufficient to prevent contamination of the cockpit. In a scenario simulating intermittent, short production of droplets (mimicking a clinical situation of coughing or disconnection of a breathing circuit in a patient with a droplet transmitted disease), the medical crew was still exposed and sedimentation accumulated around the patient but not in the cockpit. This result indicates that the amount of aerosol determines the reach and degree of contamination. Thus, the simplified concept of airborne and droplet precautions is reasonable for clinical decisions to transport a patient by air ambulance, although more complex scenarios can be used for occupational health risk assessments in general. ${ }^{2}$ Patients with an illness requiring airborne precautions should only be transported in air ambulance helicopters with a physical separation of cockpit and cabin. The curtain used for night vision goggle (NVG) flights in an H145 or H135 helicopter in our simulation seems to have been sufficient to prevent aerosols from entering the cabin. Procedural instructions for chemo-thermal washing and/or disinfection of curtains or separation walls should be developed.

Our study was limited by the model used for aerosol generation and by the number and duration of flights. Although we were able to simulate many real-life conditions on the ground and during flight, these experimental conditions clearly differ from those in commercial airplanes. ${ }^{3}$ In light of recent findings about virus shedding in exhaled breath, ${ }^{4}$ it seems unlikely that those aerosols would reach the cockpit just from intermittent coughing or exhalation. This risk could be further reduced if the patient wears a mask, which is recommended as part of droplet precautions. Personal protective equipment is required for the medical crew. Also, thorough cleaning of all surfaces is necessary in the cabin after transport because the contamination risk seems to be much higher in the confined helicopter cabin space compared to a normal hospital room where contamination is frequently found during routine care. ${ }^{5}$

\section{Acknowledgments.}

Financial support. This work was funded by institutional funds only.

Conflicts of interest. S.S.S. is shareholder of BZH-Beteiligungs-GbR and receives royalties from Springer, Thieme, and Kohlhammer.

\section{References}

1. Schulz-Stübner S, Kosa R, Henker J, Mattner F, Wendel AF. Is UV-C "light wand" mobile disinfection in air ambulance helicopters effective? Infect Control Hosp Epidemiol 2019;40:1323-1331.

2. Jones RM, Brosseau LM. Aerosol transmission of infectious disease. J Occup Environ Med 2015;57:501-508.

3. Sze To GN,Wan, MP Chao CYH, Fang L, Melikov A. Experimental study of dispersion and deposition of expiratory aerosols in aircraft cabins and impact on infectious disease transmission. Aerosol Sci Technol 2009;43: 466-485.

4. Leung NHL, Chu DKW, Shiu EYC, et al. Respiratory virus shedding in exhaled breath and efficacy of face masks. Nat Med 2020 Apr 3 [Epub ahead of print]. doi: 10.1038/s41591-020-0843-2.

5. Phan LT, Sweeney DM, Maita DM et al. Respiratory virus in the patient environment. Infect Control Hosp Epidemiol 2020;41:259-266. 